\title{
EFFECT OF PALLETIZED MAP STORAGE ON THE QUALITY AND NUTRITIONAL COMPOUNDS OF THE JAPANESE PLUM CV. ANGELENO (PRUNUS SALICINA LINDL.)
}

\author{
CRISTIANA PEANO, ${ }^{1}$ NICOLE ROBERTA GIUGGIOLI, ${ }^{1,4}$ VINCENZO GIRGENTI, ${ }^{1}$ AMEDEO PALMA, ${ }^{2}$ \\ SALVATORE D'AQUINO ${ }^{2}$ and FRANCESCO SOTTILE ${ }^{3}$ \\ ${ }^{1}$ Department of Agricultural, Forest and Food Sciences, University of Torino, Largo Paolo Braccini 2, Grugliasco (TO) 10095, Italy \\ ${ }^{2}$ Institute of Sciences of Food Production, National Research Council, Traversa La Crucca 3, Regione Baldinca, 07040 Li Punti, Sassari, Italy \\ ${ }^{3}$ Department of Agricultural and Forest Sciences, University of Palermo, Viale delle Scienze, 11, 90128 Palermo, Italy
}

\author{
${ }^{4}$ Corresponding author. \\ TEL: + 39.011.670.8646; \\ FAX: + 39.011.670.8658; \\ EMAIL: nicole.giuggioli@unito.it
}

Received for Publication July 22, 2015

Accepted for Publication December 8, 2015

doi:10.1111/jfpp. 12786

\begin{abstract}
The influence of active modified atmosphere packaging MAP $\left(10.0 \mathrm{kPa}\right.$ of $\mathrm{O}_{2}$ and $5 \mathrm{kPa}$ of $\mathrm{CO}_{2}$ ) on palletized system was evaluated to extend the marketability of fresh plums cv. Angeleno. Fruits were wrapped with a polyethylene film in pallet bag units at $1 \mathrm{C}$ and $90 \%$ relative humidity for up to 60 days. The gas values of the pallet bags, the fruit weight losses and their qualitative and nutraceutical characteristics were periodically monitored to evaluate the goodness of storage. The results showed as the pallet bag have maintained the market life of Angeleno plums to up to 60 days, preserving the most important qualitative traits of fruits. After 20, 40 and 60 days the MAP treatment maintained the pulp harder than control fruits respectively of $0.87,0.75$ and $0.46 \mathrm{~kg} / \mathrm{cm}^{2}$ and the SUAC index (quotient of the sum of sugars and sum of acids) was unaffected by the gas composition.
\end{abstract}

\section{PRATICAL APPLICATIONS}

The storage in pallet under different MAP conditions could be a promising technique for plums and specifically allows different items with different technical requirements to be stored in the same cold-storage room. Furthermore, the storage units could also be conveniently used for the fruit transport along the entire supply chain to reach markets far from production areas.

\section{INTRODUCTION}

Plums (L.) are stone fruits whose production plays a key role in the agricultural sector of the European market. In Europe, plum production remains concentrated in Mediterranean-type areas. In Italy, in 2012, the total production was 172,247 tons (Faostat 2012). Globally, Japanese plum (Prunus salicina Lindl.) production is larger than that of European plums (Prunus domestica L.). These fruits are generally destined for fresh consumption (Sottile et al. 2010a; Fanning et al. 2014). Various studies have shown that Japanese plums are significant sources of dietary anthocyanins (Venter et al. 2013; Fanning et al. 2014) and nutraceutical compounds (Treutter et al. 2012), but little information is available about their evolution under the most common storage conditions such as modified atmosphere packaging
(MAP) (Díaz-Mula et al. 2009; Sottile et al. 2010b; Singh and Singh 2012). As the market for fresh produce is growing steadily, it is very important to improve postharvest handling and shelf-life, both to maintain orderly marketing and, depressed markets but also to meet buyer requirements, to extend the marketing season to guarantee fruit quality and to satisfy the consumer's requirements.

Transport results in an extension of the plum's storage. Because both the transport and storage phases affect the conservation of the fruit's visual as well as nonvisual attributes (Awad and de Jager 2003), their conditions should be similar to preserve the fruit's postharvest life and thus advances in logistics and packaging technologies are necessary in both sectors. The commercial life of plums changes with cultivars but generally if stored at $0 \mathrm{C}$, the fruit of most 


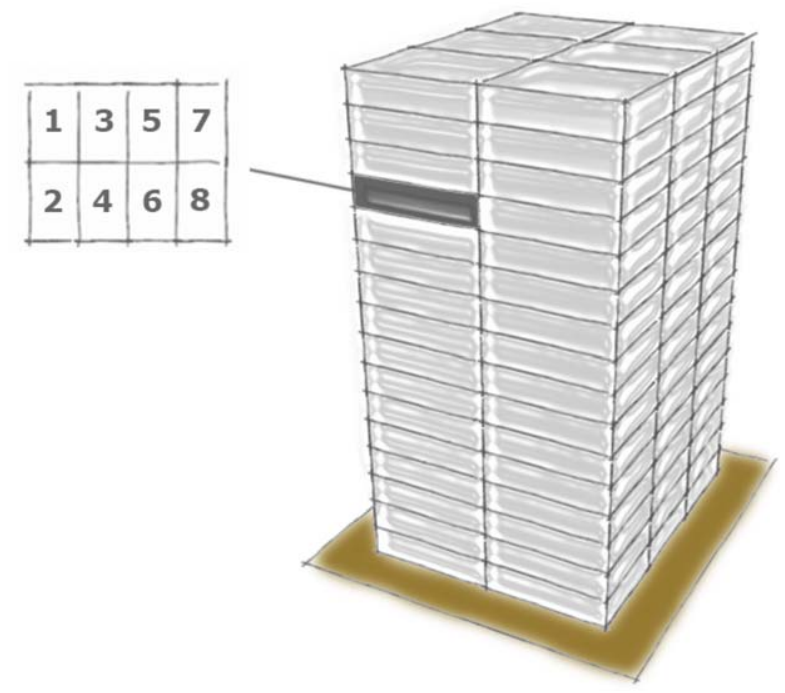

FIG. 1. SAMPLE PREPARATION OF PLUMS CV. ANGELENO IN THE PALLET UNIT STORAGE

of Japanese cultivars can be maintained for up to 6 weeks (Crisosto et al. 1995; Abdi et al. 1997). Among the different postharvest treatments that aim to reduce fruit diseases, the use of controlled atmosphere (CA) has been largely applied (Eksteen et al. 1986; Streif 1989; Ben and Gaweda 1992; Truter et al. 1994); in the same way, transport bulk packaging systems configured as pallet bags under modified atmosphere (MA) can be successfully used to improve the shelf life of fresh produce during distribution and storage (Lee et al. 1996; Peano et al. 2010; Selcuk and Erkan, 2015). In previous studies, different pallet cover systems were applied together with low temperature to maintain high $\mathrm{CO}_{2}$ levels and to preserve the quality of strawberries during transport (Macnish et al. 2012). Furthermore, the effects of palliflex controlled atmosphere storage system were actually investigated to store medlar fruits for up to 60 days (Selcuk and Erkan 2015). A palletized MAP storage that functions throughout the entire supply chain (room storage and transport) could improve the fresh plum market. In this study, we evaluated the effects of a long storage in pallets under MAP conditions of plums cv. Angeleno on various quality attributes and nutraceutical compounds.

\section{MATERIALS AND METHODS}

\section{Harvesting and Selection Conditions}

The plum fruits were collected in a commercial orchard in Saluzzo (Cuneo, Piedmont). The fruits were picked by hand in the middle of September and were selected based on size uniformity and absence of damage. The fruits were placed in polyethylene terephthalate (PET) trays and transported to the packinghouse in less than $1 \mathrm{~h}$. The different storage treatments initiated approximately $3 \mathrm{~h}$ after harvest.

\section{Sample Preparation}

The plums were packaged in rigid ventilated PET trays (size $9.5 \times 16 \times 8 \mathrm{~cm})$ containing $0.500 \mathrm{~kg}$ of fruits each. Eight PET trays were put into a cardboard flat. Six flats were assembled in a single layer on a $100 \times 120 \mathrm{~cm}$ wood pallet base. A total of 16 layers of six flats each were stacked onto the storage unit of each pallet (treatment) (Fig. 1).

\section{Pallet Treatments and Storage Conditions}

The plums were divided into two groups. The first group was palletized in the active modified atmosphere (palletized MAP treatment). The pallet was wrapped with a $100 \mu \mathrm{m}$ thick polyethylene film (PE) (thermally sealed at the base). It was injected via a flow-through system that operates with a high and low-pressure side, using $\mathrm{CO}_{2}$ and $\mathrm{O}_{2}$ gases, to modify the atmosphere in order to have an initial gas value of $10.0 \mathrm{kPa} \mathrm{O}_{2}$ and $5 \mathrm{kPa} \mathrm{CO}$. The air in the envelope was partially removed and substituted with the desired gas mixture. The $\mathrm{O}_{2}\left(\mathrm{O}_{2} \mathrm{TR}\right)$ and $\mathrm{CO}_{2}\left(\mathrm{CO}_{2} \mathrm{TR}\right)$ transmission rates of the PE film were calculated with a Multiperm Oxygen and Carbon Dioxide Analyzer (Extra Solution s.r.l., Pisa, Italy) at $23 \mathrm{C}$ and at $50 \%$ relative humidity $(\mathrm{RH})$. The $\mathrm{O}_{2} \mathrm{TR}$ measurement based on an ASTM F 2622-08 was $1572 \mathrm{~cm}^{3}$ / $\mathrm{m}^{2} / \mathrm{d} / \mathrm{bar}$, while the $\mathrm{CO}_{2}$ TR based on an ASTM F 2476-05 was $6111 \mathrm{~cm}^{3} / \mathrm{m}^{2} / \mathrm{d} /$ bar. The water vapor barrier of the $\mathrm{PE}$ film, as suggested by Van Tuil et al. (2000), was classified as a high barrier. The second group of plums was not wrapped, and was maintained under normal atmosphere conditions (NA), thus serving as a control. All samples were stored for 60 days in a cold and dark room at $1 \pm 1 \mathrm{C}$ and $90-95 \% \mathrm{RH}$. All analyses, with the exception of determination of the atmosphere inside the pallet (every 10 days up to the end of the storage), were performed at harvest (0 days) and after 20,40 and 60 days. Three replicates / treatment were made for each storage time and two flats / replicate $(n=30$; five fruits per flat) were removed at random for analyses. In Fig. 1 the diagram showing the plums for the palletized storage is reported.

\section{Evaluation of Pallet Atmosphere}

Carbon dioxide and oxygen concentrations were measured by a $\mathrm{CO}_{2}$ and $\mathrm{O}_{2}$ analyzer (CheckPoint II, PBI Dansensor, Italy). To prevent gas leakage while the measurements were being taken, an adhesive septum (Septum white $15 \mathrm{~mm}$ diameter, Dansensor, Italy) was placed on the PE film's surface. The results, expressed as $\mathrm{kPa}$, are the average of the three replicates. 


\section{Weight Loss}

Weight loss of each tray was determined using an electronic balance (SE622, WVR Science Education) with an accuracy of $0.001 \mathrm{~g}$. The weight of six trays from each treatment was recorded at harvest and at the end of each storage period. Weight loss was expressed as the percentage reduction of the initial weight.

\section{Fruit Flesh Firmness, Total Soluble Solids and Titratable Acidity}

Fruit flesh firmness (FFF) was measured using an Effegi hand-held penetrometer (Facchini, Alfonsine, Italy) equipped with an $8-\mathrm{mm}$ plunger and expressed as $\mathrm{kg} / \mathrm{cm}^{2}$. Each value is the average of two measurements taken from opposite sides of each fruit. No skin was removed from each measurement site prior to measuring.

The total soluble solids (TSS) were determined by a digital pocket refractometer (Atago, Co., Ltd., Tokyo, Japan) calibrated at $20 \mathrm{C}$ to $0 \%$ with distilled water. Two readings were taken on each fruit and averaged. Values were expressed as ${ }^{\circ}$ Brix at $20 \mathrm{C}$.

The titratable acidity (TA, meq/L) was measured using an automatic titrator (Titritino 702, Metrohm, Swiss) by titrating $5 \mathrm{~mL}$ of juice diluted in $25 \mathrm{~mL}$ of distilled water with $0.1 \mathrm{~N} \mathrm{NaOH}$ to an end point of $\mathrm{pH} 8.1$.

\section{Total Phenols, Antioxidant Capacity and Anthocyanins}

The plums were frozen in liquid nitrogen, lyophilized and powdered using a domestic mixer and, finally stored at $20 \mathrm{C}$ until further analysis. About $0.25 \mathrm{~g}$ of lyophilized sample was diluted in $25 \mathrm{~mL}$ of aqueous methanol $(20: 80 \mathrm{v} / \mathrm{v})$ (Carlo Erba, Milan, Italy). The sample was stirred for $1 \mathrm{~h}$, and centrifuged at 12,000 rpm for $15 \mathrm{~min}$ and the supernatant was collected for analysis prior to filtration with a $0.45 \mu \mathrm{m}$ nylon filter. The extractions were performed under reduced light conditions and all analyses were conducted in triplicate for all parameters.

The total phenolic compounds were determined using the Folin-Ciocalteau reagent (Singleton and Rossi 1965). Values were expressed as gallic acid equivalents (GAE). The absorbance was determined at $760 \mathrm{~nm}$.

Antioxidant activity was assessed using the free radical 2,2' diphenyl-1-picrylhydrazyl (DPPH) (Bonded et al. 1997). The mixture, containing $3 \mathrm{~mL}$ of a methanol solution of $0.16 \mathrm{mM}$ $\mathrm{DPPH}$ and $0.05 \mathrm{~mL}$ of sample extract, was allowed to react in a cuvette; the absorbance of the DPPH solution was determined at $515 \mathrm{~nm}$ after $15 \mathrm{~min}$ of reaction. Trolox (6-hydroxy2,5,7,8-tetramethylchroman-2-carboxylic acid) was used as a reference to compare the antioxidant activity. The activity was expressed as $\mathrm{mM}$ Trolox equivalent antioxidant activity (TEAC) related to $1 \mathrm{~g}$ of lyophilized sample.

Total anthocyanins were determined via a spectrophotometric method (Rapisarda et al. 1994) using a UV-Vis spectrophotometer (Cary 50, Varian Australia, Ltd., Victoria, Australia). An aliquot of juice $(1 \mathrm{~mL})$ was diluted up to $10 \mathrm{~mL}$ to a $\mathrm{pH}$ of 1 for the solution $(25 \%$ of $0.2 \mathrm{M} \mathrm{KCl}$ and $75 \%$ of $0.2 \mathrm{M} \mathrm{HCl})$. A second aliquot $(1 \mathrm{~mL})$ was diluted up to $10 \mathrm{~mL}$ with a $\mathrm{pH}$ of 4.5 in a buffered solution $(40 \%$ of $1 \mathrm{M} \mathrm{CH}_{3} \mathrm{CO}_{2} \mathrm{Na}, 24 \%$ of $1 \mathrm{M} \mathrm{HCl}$ and $36 \%$ of $\mathrm{H}_{2} \mathrm{O}$ ). Absorbance of the solutions was measured at $510 \mathrm{~nm}$. Concentration of anthocyanins was calculated through the difference of absorbance at $510 \mathrm{~nm}$ between $\mathrm{pH} 1$ (colored oxonium or flavylium form) and $\mathrm{pH} 4.5$ (colorless carbinol form) solutions; results were expressed as cyanidin 3glucoside (C3G).

Anthocyanin determination was performed via LaChrom Merck-Hitachi liquid chromatograph (Hitachi, Ltd., Tokyo, Japan) with a L-7455 photodiode detector (DAD). A Luna C18column $(150 \mathrm{~mm} \times 4.6 \mathrm{~mm}, 3 \mu \mathrm{m}$, Phenomenex, Castel Maggiore, BO, Italy), equipped with a precolumn $(7.5 \mathrm{~mm} \times 4.6 \mathrm{~mm}$ I.D.) was employed. The HPLC elution was carried out at $35 \mathrm{C}$ by using the following elution profile: flow rate $0.5 \mathrm{~mL} / \mathrm{min}, t=010 \%$ solvent $\mathrm{B}$ (acetonitrile)/ 90\% solvent A (trifluoroacetic acid 0.1\%, acetic acid $0.2 \%), t=20 \mathrm{~min} 20 \% \mathrm{~B}$ linear gradient, $t=38 \mathrm{~min} 32 \% \mathrm{~B}, t=5010 \% \mathrm{~B}$, post time $12 \mathrm{~min}$. The chromatogram was monitored simultaneously at 280, 360 and $520 \mathrm{~nm}$. Quantitative analysis of anthocyanins was carried out using the external standards method and their concentration was expressed as cyanidin-3-glucoside equivalents. Calculation of concentrations for cyanidin 3glucoside, cyanidin 3,5-diglucoside and pelargonidin 3glucoside was based on external standards, while the concentration of the other anthocyanins was expressed as cyanidin 3-glucoside equivalents. Anthocyanins were identified by LC-electrospray ionisation (ESI)-MS analysis using an Agilent Technologies (Palo Alto, CA, USA) 1100 series LC/MSD equipped with a diode-array detector (DAD).

\section{Sugars and Organic Acids}

Analyses of carbohydrates were performed by coupling a liquid chromatograph system consisting of a D-7000 manager, L-7100 pump, L7200 autosampler (LaChrom, MerckHitachi, Ltd., Tokyo, Japan) with an evaporative light scattering detector (ELSD Sedex 60Lt, Alfortville, France). A BioRad aminex fast carbohydrate column $100 \mathrm{~mm} \times 7.8 \mathrm{~mm}$, $9 \mu \mathrm{m}$, Bio-rad, Milan, Italy) with a guard column (Bio-rad micro-guard Carbo-P aminex cation exchange resin, lead form) held at $80 \mathrm{C}$, was employed. The isocratic mobile phase was ultrapure water purified via the MilliQ system (Waters, 
Milford, MA) with a flow rate of $0.8 \mathrm{~mL} / \mathrm{min}$. The isocratic mobile phase was $\mathrm{H}_{2} \mathrm{O}$ ultra-pure, and a flow rate of $0.8 \mathrm{~mL}$ / min was employed. The ELSD detector was set as follows: drift tube temperature 45C; nebulizer gas (air) pressure: 2.5 bar and photomultiplier 8 . Stock standard solutions of each carbohydrate were prepared in ultra-pure water and their quantification was calculated according to the linear calibration curves of standard compounds. The analyses were conducted in triplicate for all parameters.

Organic acids were determined with a Merck-Hitachi (Tokyo, Japan) liquid chromatograph with an L-7455 photodiode detector (DAD) detector, D-7000 system manager, L7200 autosampler and L-7100 pumps. Simultaneous separation and determination of organic acids were achieved according to the procedure described by Yuan and Chen (1999) and by Chinnici et al. (2005) using a Bio-Rad cation guard column and a Bio-Rad Aminex HPX-87H Hydrogen form cation exchange resin-based column ( $300 \mathrm{~mm} \times 7.8 \mathrm{~mm}$ i.d. $)$ at $40 \mathrm{C}$.

The mobile phase consisted of $0.005 \mathrm{M}$ sulphuric acid aqueous solution and the samples were isocratically separated at $0.6 \mathrm{~mL} / \mathrm{min}$. Peaks of organic acids were measured at wavelengths of $210 \mathrm{~nm}$ and were identified by comparing retention times with those of standards and quantification was carried out using external standards.

From the data of individual sugars and individual organic acids, sums of sugars and of acids were calculated.

The SUAC index was calculated as the quotient of the sum of sugars and sum of acids.

\section{Sensory Evaluations (Consumer Assesment)}

In order to have additional parameters for evaluating the quality of fruits six panelists previously trained with commercial samples were invited to perform a sensory evaluation of the fruits. Taste analysis was assessed in fruit taken out of storage after 20, 40 and 60 days. Six fruits per treatment were pealed and sectioned into segments. At least two segments from different fruits were presented to judges in trays labeled with three-digit random codes and served at room temperature $(20 \pm 1 \mathrm{C})$. The sensory descriptors used were appearance, texture, flavor, taste and overall acceptability. The sensory evaluation was performed agreeing the hedonic scale used in the store consumer test on Blackamber' plum (Prunus salicina Lindell) [Crisosto et al. 2004].

During each session, the samples were presented in randomized order to the panelists, who judged the descriptors using a nine-point hedonic scale at room temperature where $9=$ "like extremely," $7=$ "like moderately," $5=$ "neither like nor dislike," $3=$ "dislike moderately" and $1=$ "dislike extremely." The scores below 3 indicated unacceptable samples.

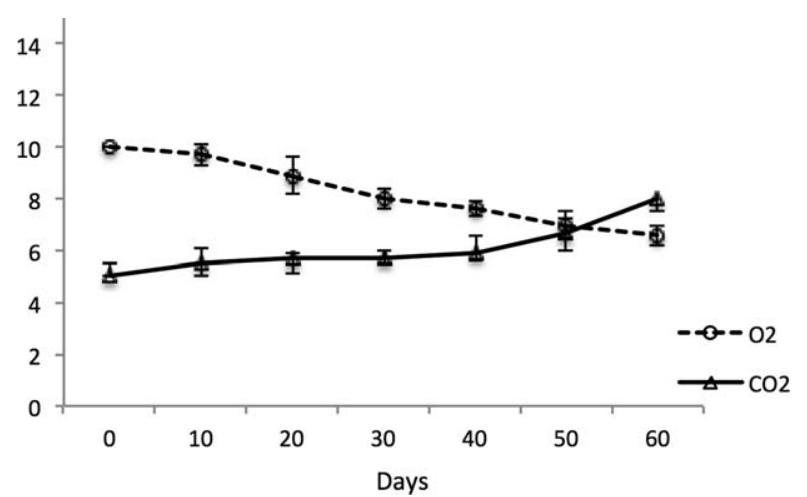

FIG. 2. $\mathrm{O}_{2}$ AND $\mathrm{CO}_{2}$ KPA INSIDE THE MAP UNITS STORAGE OF PLUMS CV. ANGELENO STORED AT $1 \pm 1 \mathrm{C}$ UP TO 60 DAYS. EACH DATA POINT REPRESENTS THE MEAN OF THREE REPLICATES. ERROR BARS REPRESENT THE STANDARD DEVIATION OF THAT MEAN $(N=3)$

\section{Statistical Analysis}

The data were subjected to a one-way analysis of variance (ANOVA) with a Tukey's test to determine the significance of the difference of the means between the groups using the IBM-SPSS.20 Software (2013). The differences were considered significant when $P<0.05$.

\section{RESULTS AND DISCUSSION}

\section{Evaluation of Pallet Atmosphere}

The $\mathrm{O}_{2}$ and $\mathrm{CO}_{2}$ levels measured inside the palletized MAP treatment along all the storage time are reported in Fig. 2. The initial atmosphere gas composition $\left(10 \mathrm{kPa} \mathrm{O}_{2}\right.$ and 5 $\mathrm{kPa} \mathrm{CO}_{2}$ ) in the pallets was a forced condition and the PE film was able to maintain the $\mathrm{O}_{2}$ and the $\mathrm{CO}_{2}$ in the range of value respectively of $10.0-6.6 \mathrm{kPa}$ and $5.0-8.0 \mathrm{kPa}$ for the entire storage time because of the complete initial seal around the pallet bases and the absence of holes in the wrapping film. The $\mathrm{CO}_{2}$ atmosphere composition inside the pallet, especially in the early stages of the storage, changed little from the start ( 0 days) because of the equilibrated mass transfer rate of the gas between the inside and the outside of the wrapping film at the low storage temperature $(1 \pm 1 \mathrm{C})$. By day 40 of storage, a decrease in the $\mathrm{O}_{2}$ headspace and an increase in the $\mathrm{CO}_{2}$ headspace into the pallet were observed, probably because of the metabolic activity of the fruits but no injurious levels of gas $\left(\mathrm{CO}_{2} \geq 15 \mathrm{kPa}\right.$ and $\left.\mathrm{O}_{2} \leq 1.0 \mathrm{kPa}\right)$ (Kader 1997) were achieved inside the MAP treatment.

\section{Fruit Weight Loss}

Plum weight loss increased over time, but its rate was treatment-dependent as showed in Fig. 3. By day 20, fruits under MAP conditions lost $0.58 \%$ of their initial weight, 


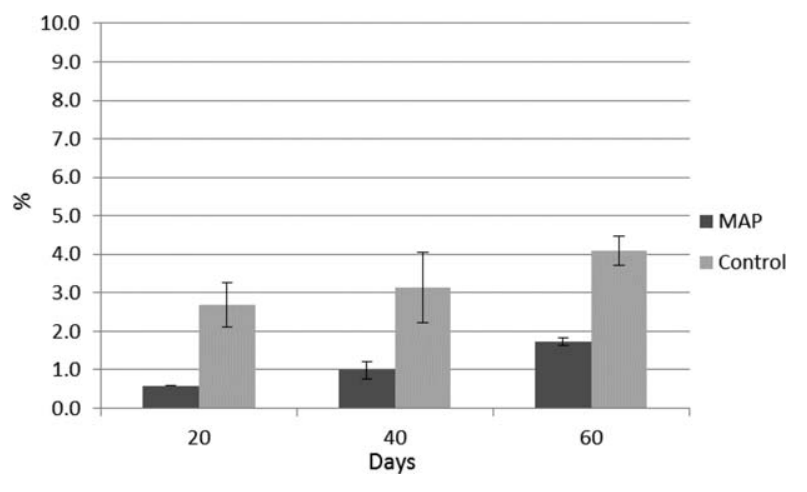

FIG. 3. WEIGHT LOSSES (\%) OF CV. ANGELENO STORED IN MAP AT 1C AND 90-95\% RH UP TO 60 DAYS

Error bars represent the standard deviation of that mean $(n=3)$.

whereas fruits stored in normal atmosphere (control) lost $2.67 \%$ of their fresh weight, showing the greatest weight loss and confirming what was observed in previous MAP studies for stone fruits (Sottile et al. 2013; Girgenti et al. 2014). In stone fruits such as peaches and nectarines, weight losses between $5 \%$ and $8 \%$ can cause visual shrivel; in this study plums were less susceptible to weight loss-induced shrivel and only the losses in the control treatment (test) may affect the cosmetic appearance of the fruit after 40 days of storage (3.12\% of weight loss)

\section{Fruit Flesh Firmness (FFF), Total Soluble Solids (TSS) and Titratable Acidity (TA)}

Fruit flesh firmness (FFF) (Table 1) significantly decreased during the storage time for both the treatments with the exception of the MAP treatment at 20 days of storage, which maintained a value similar to the harvest time $(7.50 \mathrm{~kg} /$ $\mathrm{cm}^{2}$ ). As reported in a previous study (Sottile et al. 2013) plums stored under MAP conditions showed higher pulp firmness; in fact after 20, 40 and 60 days of storage via MAP treatment, plums maintained a firmer pulp than control fruits respectively of $0.87,0.75$ and $0.46 \mathrm{~kg} / \mathrm{cm}^{2}$.

The total soluble solids content (TSS) is often used as an indicator of fruit quality and maturity stage (Crisosto and Day 2012). Plums cv. Angeleno showed $21.1^{\circ}$ Brix at harvest, and during the storage time a reduction of values was observed for all of the treatments resulting from the respiration rate as showed by the $\mathrm{CO}_{2}$ values in the pallet bag units in storage (Fig. 2). TSS ranged from a minimum value of $19.1^{\circ}$ Brix to a maximum value of $19.7^{\circ}$ Brix and no statistically significant difference was observed between the MAP and control treatments. Changes in TSS between harvest and storage time were quite low, although significant. Those slight changes associated to the fact that at harvest TSS had a high standard deviation, denote a high variability among fruit. So the little decline in TSS occurring during the first days of storage could be a response to a transient stress condition, limited to the time required to let the fruit reach the thermic equilibrium with the cold-storage room. For example, when fruits are moved from ambient temperature to cold storage, until fruit temperature gets the same values of storage temperature higher transpiration and respiration rates occurring in fruit can result in a temporary higher depletion of sugars.

Plums contain very little or no starch reserve hence there is no conversion from starch to sugar during ripening and no significant increase can be expected. As reported by Cantín et al. (2008) the titratable acidity (TA) observed at harvest $(7.57 \mathrm{meq} / \mathrm{L})$ decreased during storage, according to consumers' preferences (Crisosto and Day 2012). During the first 40 days of storage, the changes in the TA content of fruits were insignificant in all of the treatments. The reduction of TA was higher in plums stored in MAP, which showed a (5.99 meq/L) statistically significantly decline in

TABLE 1. CHANGES IN FLESH FRUIT FIRMNESS (FFF), TOTAL SOLUBLE SOLIDS (TSS), TITRATABLE ACIDITY (TA), TOTAL POLYPHENOL COMPOUNDS, TOTAL ANTHOCYANINS AND ANTIOXIDANT CAPACITY IN CV. ANGELENO PLUMS STORED IN MAP FOR UP TO 60 DAYS AT 1C AND 90-95\% RH

\begin{tabular}{|c|c|c|c|c|c|c|}
\hline Treatments & $\begin{array}{l}\mathrm{FFF} \\
\mathrm{Kg} / \mathrm{cm}^{2}\end{array}$ & $\begin{array}{l}\text { TSS } \\
{ }^{\circ} \text { Brix }\end{array}$ & $\begin{array}{l}\text { TA } \\
\text { meq/L }\end{array}$ & $\begin{array}{l}\text { Total } \\
\text { Polyphenols } \\
\text { mg/g liophylized }\end{array}$ & $\begin{array}{l}\text { Total } \\
\text { anthocyanin } \\
\text { mg/g liophylized }\end{array}$ & $\begin{array}{l}\text { Antioxidant } \\
\text { capacity } \\
\text { Trolox equivalent }\end{array}$ \\
\hline Harvest & $7.50 \pm 0.2^{* a}$ & $21.1 \pm 1.3^{a}$ & $7.57 \pm 0.5^{a}$ & $36.9 \pm 0.8^{c d}$ & $2.91 \pm 0.1^{a}$ & $0.07 \pm 0.002^{b}$ \\
\hline \multicolumn{7}{|l|}{20 days } \\
\hline MAP & $7.71 \pm 0.5^{a}$ & $19.4 \pm 0.6^{b}$ & $6.33 \pm 0.5^{a b}$ & $38.28 \pm 2.3^{\mathrm{bcd}}$ & $2.90 \pm 0.1^{a}$ & $0.07 \pm 0.002^{b}$ \\
\hline CONTROL & $6.84 \pm 0.6^{b}$ & $19.7 \pm 0.9^{b}$ & $7.44 \pm 0.2^{\mathrm{ab}}$ & $39.12 \pm 1.3^{b c}$ & $2.83 \pm 0.1^{a}$ & $0.07 \pm 0.002^{b}$ \\
\hline \multicolumn{7}{|l|}{40 days } \\
\hline MAP & $7.07 \pm 0.3^{b}$ & $19.4 \pm 0.5^{b}$ & $6.92 \pm 0.6^{\mathrm{ab}}$ & $37.06 \pm 0.7^{\mathrm{cd}}$ & $2.74 \pm 0.1^{a}$ & $0.07 \pm 0.002^{b}$ \\
\hline CONTROL & $6.32 \pm 0.2^{c}$ & $19.1 \pm 0.7^{b}$ & $7.40 \pm 0.2^{\mathrm{ab}}$ & $42.90 \pm 0.8^{a}$ & $2.90 \pm 0.1^{a}$ & $0.08 \pm 0.001^{a}$ \\
\hline \multicolumn{7}{|l|}{60 days } \\
\hline MAP & $5.90 \pm 0.5^{d}$ & $19.3 \pm 0.6^{b}$ & $5.99 \pm 0.7^{b}$ & $35.40 \pm 0.6^{d}$ & $2.36 \pm 0.1^{b}$ & $0.07 \pm 0.001^{b}$ \\
\hline CONTROL & $5.44 \pm 0.3^{e}$ & $19.2 \pm 0.5^{b}$ & $6.40 \pm 0.6^{a b}$ & $41.26 \pm 0.9^{a b}$ & $2.98 \pm 0.1^{a}$ & $0.08 \pm 0.001^{a}$ \\
\hline
\end{tabular}

* Values in columns with the same letters are not significantly different according to the Tukey's test at $P \leq 0.05$. Values are average \pm standard deviation $(n=3)$ 
TABLE 2. AVERAGE CONTENTS WITH STANDARD ERRORS OF INDIVIDUAL ANTHOCYANINS $\left(\mathrm{mg} \mathrm{g}^{-1}\right)$ IN CV. ANGELENO PLUMS STORED IN MAP UP TO 60 DAYS

\begin{tabular}{|c|c|c|c|}
\hline Treatments & Cyanidin 3-glucoside & Cyanidin 3-rutinoside & Peonidin- 3 rutinoside \\
\hline Harvest & $0.88 \pm 0.00^{a}$ & $0.54 \pm 0.02^{\mathrm{ns}}$ & $0.01 \pm 0.00^{\mathrm{ns}}$ \\
\hline \multicolumn{4}{|l|}{20 days } \\
\hline MAP & $0.93 \pm 0.03^{a}$ & $0.54 \pm 0.01^{\mathrm{ns}}$ & $0.01 \pm 0.00^{\mathrm{ns}}$ \\
\hline CONTROL & $0.92 \pm 0.04^{a}$ & $0.56 \pm 0.02^{\mathrm{ns}}$ & $0.01 \pm 0.00^{\mathrm{ns}}$ \\
\hline \multicolumn{4}{|l|}{40 days } \\
\hline MAP & $0.90 \pm 0.02^{\mathrm{a}}$ & $0.55 \pm 0.01^{\mathrm{ns}}$ & $0.01 \pm 0.00^{\mathrm{ns}}$ \\
\hline CONTROL & $0.88 \pm 0.01^{a}$ & $0.55 \pm 0.03^{\mathrm{ns}}$ & $0.01 \pm 0.00^{\mathrm{ns}}$ \\
\hline \multicolumn{4}{|l|}{60 days } \\
\hline MAP & $0.74 \pm 0.06^{b}$ & $0.52 \pm 0.00^{\mathrm{ns}}$ & $0.01 \pm 0.00^{\mathrm{ns}}$ \\
\hline CONTROL & $0.92 \pm 0.01^{\mathrm{a}}$ & $0.56 \pm 0.01^{\mathrm{ns}}$ & $0.01 \pm 0.00^{\mathrm{ns}}$ \\
\hline
\end{tabular}

*Values in columns with the same letters are not significantly different according to the Tukey's test at $P \leq 0.05$. Values are average \pm standard deviation $(n=3)$.

respect to the harvest time at the end of their storage $(60$ days). As reported in Table 2, over storage TA showed an overall slight decline which was not significant, so from the statistical point of view there was no difference and variations in average values are only because of the variability within the fruit of each treatment, which in most cases was higher than that observed between the treatments.

\section{Total Phenols, Antioxidant Capacity and Anthocyanins}

In accordance with previous studies (Tomas-Berberan et al. 2001; Usenik et al. 2008), no clear trend in the phenols content (Table 1) was observed during the storage time. Plums stored in MAP showed values lower than control fruits for the entire storage time, but significant differences were observed between treatments only after 40 days of storage. Results of this study are in agreement with previous results reported by others in plums (Díaz-Mula et al., 2009; DíazMula et al., 2011), where new synthesis of polyphenols was stimulated by low temperature and contrasted by low levels of $\mathrm{O}_{2}$ associated with increased concentrations of $\mathrm{CO}_{2}$, which is the case of MAP treatment. The antioxidant capacity (Table 1) did not change during the first 20 days of storage in both treatments. Changes between the treatments occurred at 40 and 60 days, when control fruits increased their antioxidant activity and statistically significant differences were observed. The total anthocyanin content at harvest was 2.91 ( $\mathrm{mg} / \mathrm{g}$ lyophilized) and during storage values ranged between 2.36 and $2.98 \mathrm{mg} / \mathrm{g}$. However, statistically significant differences between treatments were only observed at the end of storage when lower values were detected in the MAP fruits. Similar results were observed by Artés et al. (2006) and Díaz-Mula et al. (2011). In accordance with results by Tomas-Barberan et al. (2001), DíazMula et al. (2008) and Usenik et al. (2008) three anthocyanins were identified (Table 2 ). The cyanidine 3 -glucoside was the predominant anthocyanin at harvest $(62 \%)$ as well during the storage time, followed by the cyanidine 3rutinoside (the former ranging from 0.93 to 0.74 ; the latter between 0.56 and 0.52 ). Statistically significant differences were observed for the cyanidine 3-glucoside only after 60 days of storage, where its content was lower in the MAP treated fruits. Besides the fact that different methods used to

TABLE 3. AVERAGE CONTENTS WITH STANDARD ERRORS OF SUGARS $(\mathrm{g} / \mathrm{g})$ IN CV. ANGELENO PLUMS STORED IN MAP FOR UP TO 60 DAYS

\begin{tabular}{|c|c|c|c|c|}
\hline Treatments & Sorbitol & Fructose & Glucose & Sucrose \\
\hline Harvest & $0.13 \pm 0.002^{b c d}$ & $0.19 \pm 0.010^{d}$ & $0.17 \pm 0.008^{c}$ & $0.17 \pm 0.010^{a}$ \\
\hline \multicolumn{5}{|l|}{20 days } \\
\hline MAP & $0.12 \pm 0.014^{d}$ & $0.24 \pm 0.014^{b c}$ & $0.19 \pm 0.003^{b}$ & $0.08 \pm 0.004^{b}$ \\
\hline CONTROL & $0.15 \pm 0.004^{\mathrm{ab}}$ & $0.23 \pm 0.008^{c}$ & $0.20 \pm 0.006^{\mathrm{ab}}$ & $0.04 \pm 0.001^{c}$ \\
\hline \multicolumn{5}{|l|}{40 days } \\
\hline MAP & $0.16 \pm 0.005^{a}$ & $0.26 \pm 0.014^{\mathrm{ab}}$ & $0.19 \pm 0.010^{b}$ & $0.03 \pm 0.002^{c}$ \\
\hline CONTROL & $0.13 \pm 0.014^{c d}$ & $0.27 \pm 0.008^{a}$ & $0.21 \pm 0.006^{a}$ & $0.03 \pm 0.004^{c}$ \\
\hline \multicolumn{5}{|l|}{60 days } \\
\hline MAP & $0.16 \pm 0.004^{a}$ & $0.27 \pm 0.001^{\mathrm{abc}}$ & $0.20 \pm 0.000^{\mathrm{ab}}$ & $0.04 \pm 0.006^{c}$ \\
\hline CONTROL & $0.14 \pm 0.005^{a b c}$ & $0.26 \pm 0.001^{a}$ & $0.20 \pm 0.005^{\mathrm{ab}}$ & $0.04 \pm 0.002^{c}$ \\
\hline
\end{tabular}

*Values in columns with the same letters are not significantly different according to the Tukey's test at $P \leq 0.05$. Values are average \pm standard deviation $(n=3)$. 


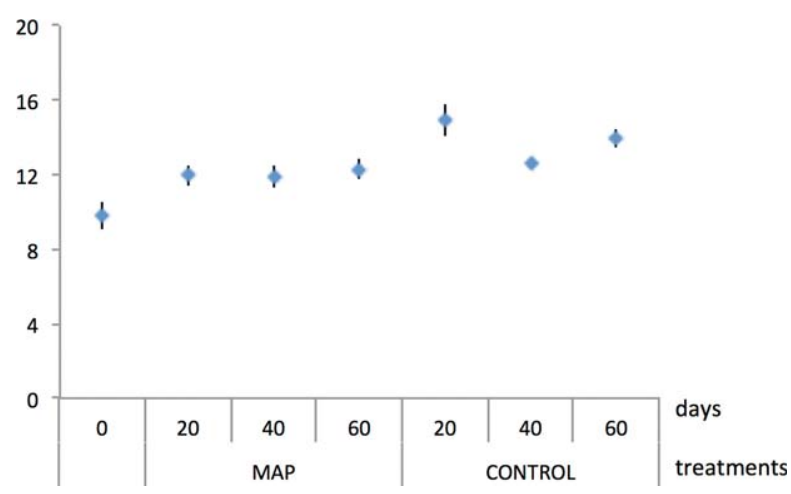

FIG. 4. AVERAGE SUAC RATIOS WITH STANDARD ERRORS FOR CV. ANGELENO PLUMS STORED IN MAP AT $1 \pm 1$ C UP TO 60 DAYS

determine anthocyanins lead to different results arising from several factors such as the different solvents, interference of polymeric pigments in the HPLC analysis, and so on (Turfan et al. 2012). In this study the apparently wide discrepancy between results obtained by spectrophotometry and those by HPLC, is because of the fact that in HPLC we quantified only the main anthocyanins but not un-known peaks of anthocyanins. In other words, the sum of the individual anthocyanins shown in Table 2 is not equivalent to total anthocyanins but represent only a part of total anthocyanins, the part composed by known anthocyanins. Among all the bioactive compounds measured, the total anthocyanins showed the best correlation with the antioxidant capacity, both for the MAP treatment $\left(R^{2}=0.644\right)$ and for the control treatment $\left(R^{2}=0.854\right)$ (data not shown).

\section{Sugars and Organic Acids}

The content and the relative composition of the individual sugars are reported in Table 3. At harvest, a balanced ratio among all of the sugars was observed; fructose (29.2\%) was the most represented, followed respectively by glucose (25.8\%), sucrose (25.6\%) and sorbitol (19.4\%).
As reported in other works, the main sugars in plums are sucrose, fructose and glucose. Anyway, when determining individual sugars we were able to identify and quantify the peak of sorbitol, which, as known, is a sugar-alcohol. Indeed, we decided to consider including this datum for the increasing interest of sorbitol as a substitute for glucose in antidiabetic diets, as well as an alternative natural sweetener to sucrose (Forni et al., 1992). The observed increase in sorbitol content over storage, however, has also been previously reported (Singh et al., 2009). Quantitative changes in sugar composition were observed over storage and between treatments for the concomitant decrease in sucrose and increase in fructose and glucose, with fructose, in agreement with results by Usenik et al. 2013, showing the highest values among the other sugars in an increasing trend. Specifically, the average percentage of sucrose decreased significantly from $25.6 \%$ to $12.4 \%$ and $4.8 \%$ respectively after 20 days of storage in the MAP and control treatments, which at the end of the storage achieved similar values $(0.004 \mathrm{~g} / \mathrm{g}$ lyophilized). The fructose and glucose concentrations showed a similar pattern of evolution in response to MAP and control treatment during the storage time compared with the sorbitol. An increasing trend during the first part of the storage (20 days) was observed for the fructose, respectively of $+12.7 \%$ (MAP) and $11.2 \%$ (control), and for the glucose $+5.2 \%$ (MAP) and $7.2 \%$ (control), followed by a plateaux of values at the end of storage in the range of $0.27-0.26$ (g/g lyophilized) for the fructose and $0.20(\mathrm{~g} / \mathrm{g}$ lyophilized) for the glucose.

The only detected organic acid was malic acid, which at harvest was $0.05 \mathrm{~g} / \mathrm{g}$ lyophilized and which did not show appreciable changes in the control fruit nor in the MAP ones during storage (data not shown).

Figure 4 reports the SUAC index, which is considered, along with the ripening index, as one of the most important influences on the aromatic profile as well as consumers' acceptance of most stone fruit species including plums (Robertson et al. 1992; Crisosto et al. 2004; Crisosto et al. 2007 and Usenik et al. 2008).

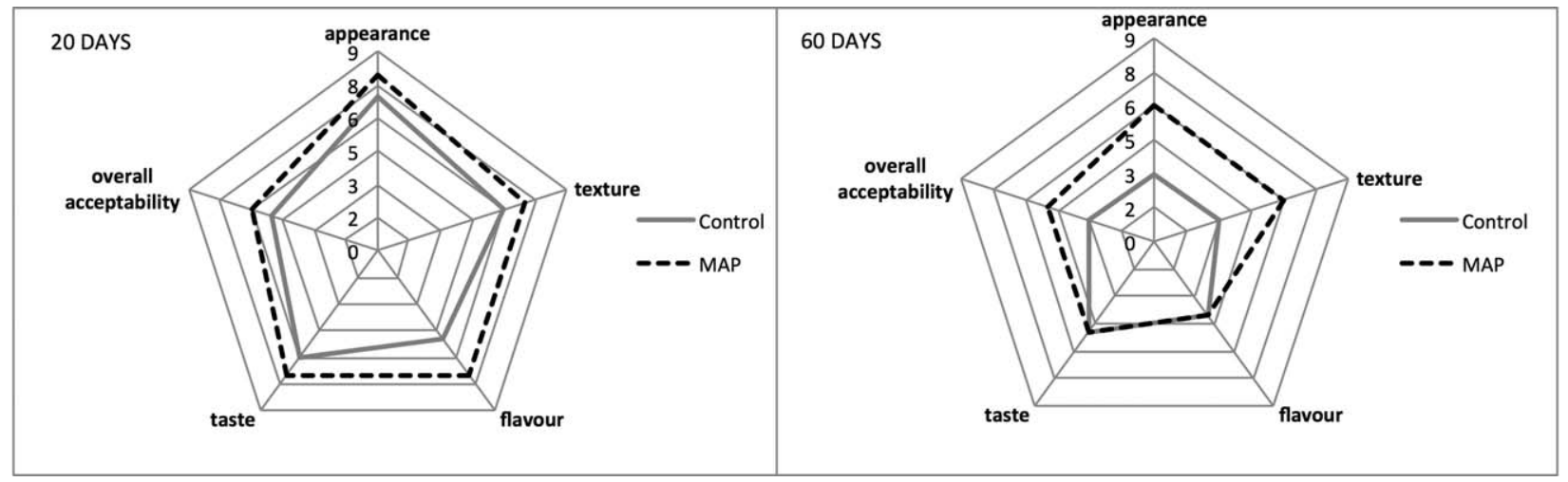

FIG. 5. SENSORY EVALUATIONS OF ANGELENO AFTER 20 AND 60 DAYS OF STORAGE 
Our results show a sharp increase of the SUAC index during the first 20 days of storage, which did not change thereafter in MAP. While it fluctuated in the control, higher values than MAP were persistent. A similar overall trend was reported by Díaz-Mula et al. (2008), who detected lower SUAC index values in fruit stored in MAP than in control treatment with a positive effect on flavor because a relatively high level of acidity is an important factor in plum quality (Díaz-Mula et al. 2008).

\section{Sensory Evaluations (Consumer Assesment)}

In general, sensory analysis is a good tool to evaluate the impact on consumer acceptability. Sensory evaluation was performed to see if $\mathrm{CO}_{2}$ affected the plums quality. It is seen from Fig. 5 that among the control and MAP samples, all the mean scores of sensory attributes recorded a decrease during the storage time. After 60 days only MAP samples maintained marketable quality parameters and texture and appearance were the most limiting factor of plums acceptability. According to FFF measurement (Table 1) Angeleno in MAP showed higher texture acceptability and more attractive color probably because of the maintenance of wax and their luminescence because of the lowest weight losses.

\section{CONCLUSION}

In this study, the use of pallets in MAP maintained at a low temperature $(+1 \mathrm{C})$ was an effective technique for extending the storage of plums cv. Angeleno for a longer time. The polyethylene film was able to manage the initial atmosphere composition in the pallet and no saturated moisture conditions resulted in the plums' surface cracking. The MAP treatments limited decreases in pulp firmness, maintaining the most important qualitative characteristics for the entire storage time and the high levels of $\mathrm{CO}_{2}$ detected in the pallet did not affect significantly changes in the content of sugars during the storage. The storage in pallets under MAP conditions could be a suitable and economic system to save space and energy in the refrigerated warehouse because it could be used to store different fruits and vegetables in the same storage room, providing different atmosphere compositions for individual pallets. This information provides guidance to improve the postharvest supply chain of fresh plums fruits.

\section{ACKNOWLEDGMENTS}

This work has been funded by the Italian Ministry of Education, University and Research (MIUR) through the PRIN research program - Quality and Safety Monitoring of the Fruit Supply Chain: New Technologies For Post-Harvest Management. The authors thank Agrifrutta Soc. Cop. Agr. for their technical support and for the use of their storage facilities.; they are also grateful to Cassandra Funsten (BA at UC Berkley) for her fundamental assistance editing the English of the final version of the paper.

\section{REFERENCES}

ABDI, N., HOLFORD, P. and MCGLASSON, W.B. 1997. Effects of harvest maturity on the storage life of Japanese-type plums. Aust. J. Exp. Agric. 37, 391-397.

ARTéS, F., GóMEZ, P.A. and ARTéS-HERNáNDEZ, F. U. 2006. Modified atmosphere packaging of fruits and vegetables. Stewart Postharvest Rev. 5, 2.

ASTM. 2005. ASTM F2476-05. Test method for the determination of carbon dioxide gas transmission rate $\left(\mathrm{CO}_{2} \mathrm{TR}\right)$ through barrier materials using an infrared detector, American Society for Testing and Materials, Philadelphia, PA.

ASTM. 2008. ASTM F2622-08. Standard test method for oxygen gas transmission rate through plastic film and sheeting using various sensors, American Society for Testing and Materials, Philadelphia, PA.

AWAD, M.A. and DE JAGER, A. 2003. Influences of air and controlled atmosphere storage on the concentration of potentially healthful phenolics in apples and other fruits. Postharvest Biol. Technol. 27, 53-58.

BEN, J. and GAWEDA, M. 1992. Effect of increasing concentrations of $\mathrm{CO}_{2}$ in controlled atmosphere storage on the development of physiological disorders and fungal diseases in plums (Prunus domestica L.). Folia Hort. 4, 87-100.

BONDET, V., BRAND-WILLIAMS, W. and BERSET, C. 1997. Kinetics and mechanism of antioxidant activity using the DPPH free radical method. Lebensm-Wiss. Technol. 30, 609-615.

CANTíN, C.M., CRISOSTO, C.H. and DAY, K.R. 2008. Evaluation of the effect of different modified atmosphere packaging box liners on the quality and shelf life of 'Friar' plums. Hort. Technol. 18, 261-265.

CHINNICI, F., SPINABELLI, U., RIPONI, C. and AMATI, A. 2005. Optimization of the determination of organic acids and sugars in fruit juices by ion-exclusion liquid chromatography. J. Food Comp. Anal. 18,121-130.

CRISOSTO, C.H., MITCHELL, F.G. and JOHNSON, S. 1995. Factors in fresh market stone fruit quality. Postharvest News Inform. 6, 17 N-21 N.

CRISOSTO, G.M., CRISOSTO, C.H., ECHEVERRIA, G. and PUY, J. 2007. Segregation of plum and pluot cultivars according to their organoleptic characteristics. Postharvest Biol. Technol. 44, 271-276.

CRISOSTO, C.H., GARNER, D., CRISOSTO, G.M. and BOWERMAN, E. 2004. Increasing 'Blackamber' plum (Prunus salicina Lindell) consumer acceptance. Postharvest Biol. Technol. 34, 237-244.

CRISOSTO, C.H. and DAY, K.R. 2012. Crop post-harvest: science and technology. In Stone Fruit (D. Rees, G. Farrell, and J. Orchard, eds.) pp. 212-225, Wiley-Blackwell, Oxford, UK. 
DÍAZ-MULA, H.M., ZAPATA, P.J., GUILLÉN, F., CASTILLO, S., MARTÍNEZ-ROMERO, D., VALERO, D. and SERRANO, M. 2008. Changes in physicochemical and nutritive parameters and bioactive compounds during development and on-tree ripening of eight plum cultivars: A comparative study. J. Sci. Food Agric. 88, 2499-2507.

DÍAZ-MULA, H.M., ZAPATA, P.J, GUILLÉN, F., MARTÍNEZ-ROMERO, D., CASTILLO, S., SERRANO, M. and VALERO, D. 2009. Changes in hydrophilic and lipophilic antioxidant activity and related bioactive compounds during postharvest storage of yellow and purple plum cultivars. Postharvest Biol. Technol. 51, 354-363.

DÍAZ-MULA, H.M., ZAPATA, P.J., GUILLÉN, F., VALVERDE, J.M., VALERO, D. and SERRANO, M. 2011. Modified atmosphere packaging of yellow and purple plum cultivars. 2 . Effect on bioactive compounds and antioxidant activity. Postharvest Biol. Technol. 61, 110-116.

EKSTEEN, G.J., VISAGIE, T.R. and LASZLO, J.C. 1986. Controlled atmosphere storage of South African grown nectarines and plums. Deciduous Fruit Grower, 36, 128-132.

FANNING, K., TOPP, B., RUSSELL, D., STANLEY, R. and NETZEL, M. 2014. Japanese plums (Prunus Salicina Lindl.) and phytochemicals - breeding, horticultural practice, post-harvest storage, processing and bioactivity. J. Sci. Food Agric. 94, 2137-2147.

FAO. 2012 FAOSTAT, FAO statistical databases. Available at: http://faostat.fao.org/site/339

FORNI E., ERBA M.L, MAESTRELLI A. and POLESELLO A., 1992. Sorbitol and free sugar contents in plums. Food Chem. 44, 269-275.

LEE, L. ARULT, J., LENCKI, R. and CASTAIGNET, F. 1996. A Review on modified atmosphere packaging and preservation of fresh fruits and vegetables: physiological basis and practical aspects-PartII. Packag. Technol. Sci. 9, 1-17.

GIRGENTI, V., PEANO, C. and GIUGGIOLI, N. 2014. Experiences of innovative packaging materials on apricot fruits $\left(\mathrm{cv}\right.$ Tom $\left.\operatorname{Cot}^{\circledR}\right)$. Fruits 69, 1-16.

KADER, A.A. 1997. A summary of CA requirements and recommendations for fruits other than apples and pears. In Proceedings of Seventh International Controlled Atmosphere Research Conference (A.A. Kader, ed.) University of California, Davis, pp. 1-34.

MACNISH, A.J., PADDA, M.S., PUPIN, F., TSOUVALTZIS, P.I., DELTSIDIS, A.I., SIMS, C.A., BRECHT, J.K. and MITCHAM, E.J. 2012. Comparison of pallet cover systems to maintain strawberry fruit quality during transport. Hort. Technol. 4, 493-501.

PEANO, C., GIRGENTI, V., SOTTILE, F. and GIUGGIOLI, N. 2010. Improvement of plum storage with modified atmosphere packaging. Acta Hort. 876, 183-188.

PUERTA-GOMEZ, A. and CISNEROS-ZEVALLOS, L. 2011. Postharvest studies beyond fresh market eating quality: Phytochemical antioxidant changes in peach and plum fruit during ripening and advanced senescence. Postharvest Biol. Technol. 60, 220-224.
RAPISARDA, P., FALLICO, B., IZZO, R. and MACCARONE, E. 1994. A simple and reliable method for determining anthocyanins in blood orange juices. Agrochimica 38, 157-164.

ROBERTSON, J.A., MEREDITH, F.I., SENTER, S.S. OKIE, W.R. and NORTON, J.D. 1992. Physical, chemical and sensory characteristics of Japanese-type plums growing in Georgia and Alabama. J. Sci. Food Agric. 60, 339-347.

SELCUK, N. and ERKAN, M. 2015. The effects of modified and palliflex controlled atmosphere storage on postharvest quality and composition of 'Istanbul' medlar fruit. Postharvest Biol. Technol. 99, 9-19.

SINGH S.P., SINGH Z. and SWINNY E. E. 2009. Sugars and organic acids in Japanese plums (Prunus salicinaLindell) as influenced by maturation, harvest date, storage temperature and period. Int. J. Food Sci. Technol. 44, 1973-1982.

SINGH, S.P. and SINGH, Z. 2012. Postharvest oxidative behaviour of 1-methylcyclopropene treated Japanese plums (Prunus salicina Lindell) during storage under controlled and modified atmospheres. Postharvest Biol. Technol. 74, 26-35.

SINGLETON, V.L. and ROSSI, J.A. 1965. Colorimetry of total phenolics with phosphomolybdic - phosphotungstic acid reagents. Am. J. Enol. Viticult. 16, 144-158.

SOTTILE, F., PEANO, C., MEZZETTI, B., CAPOCASA, F., BELLINI, E., NENCETTI, V., PALARA, U., PIRAZZINI, P., MENNONE, C. and CATALANO, L. 2010a. Plum production in Italy: State of art and perspectives. Acta Horti. 874, $25-36$.

SOTTILE, F., IMPALLARI, M., PEANO, C. and GIUGGIOLI, N. 2010b. Antioxidant compounds and qualitative traits in European (Prunus domestica L.) and Japanese (P. triflora) plum fruits as affected by cold storage. Acta Horti. 877, 1145-1152.

SOTTILE, F., PEANO, C., GIUGGIOLI, N.R. and GIRGENTI, V. 2013. The effect of modified atmosphere packaging on the physical and chemical quality of fresh yellow plum cultivars. J. Food Agric. Environ. 11, 363-367.

STREIF, J. 1989. Storage behaviour of plum fruits. Acta Horti. 258, 177-183.

TOMAS-BARBERAN, F.A., GIL, M.I., CREMIN, P., WATERHOUSE, A.L., HESS-PIERCE, B. and KADER, A.A. 2001. HPLC-DAD-ESIMS analysis of phenolic compounds in nectarines, peaches and plums. J. Agric. Food Chem. 49, $4748-4760$.

TREUTTER, D., WANG, D., FARAG, M.A., ARGUETA BAIRES, G.D., RÜHMANN, S. and NEUMÜLLER, M. 2012. Diversity of phenolic profiles in the fruit skin of Prunus domestica plums and related species. J. Agric. Food Chem. 60, 12011-12019.

TRUTER, A.G., COMBRINK, J.C. and VON MOLLENDORFF, L.J. 1994. Controlled-atmosphere storage of plums.

Deciduous Fruit Grower 44, 373-375.

TURFAN, O., TURKYILMAZ, M., YEMIS, O., ÖZKAN, M., 2012. Effects of clarification and storage on anthocyanins and color of pomegranate juice concentrates. J. Food Qual. 35, 272-282. 
USENIK, V., KASTELEC, D., VEBERIC, R. and STAMPAR, F. 2008. Quality changes during ripening of plums (Prunus domestica L.). Food Chem. 111, 830-836.

USENIK, V., STAMPAR, F. and KASTELEC, D. 2013.

Phytochemicals in fruits of two Prunus domestica L. plum cultivars during ripening. J. Sci. Food Agric. 93,681-692.

VAN TUIL, R., FOWLER, P., LAWTHER, M. and WEBER, C.J. 2000. Properties of biobased packaging materials. In Biobased Packaging Materials for the Food Industry Status and Perspectives (C.J. Weber ed.) pp. 8-33, KVL, Frederiksberg. VENTER, A., JOUBERT, E. and DE BEER, D. 2013. Characterisation of phenolic compounds in South African plum fruits (Prunus salicina Lindl.) using HPLC coupled with diode-array, fluorescence, mass spectrometry and on-line antioxidant detection. Molecules, 18, 5072-5090.

WANG, H., NAIR, M., STRASBURG, G., CHANG, Y., BOOREN, A., GRAY, J. and DEWITT, D. 1999. Antioxidant and antiinflammatory activities of anthocyanins and their aglycon, cyanidin from tart cherries. J. Nat. Products 62, 294-296.

YUAN, J.P. and CHEN, F. 1999. Simultaneous separation and determination of sugars, ascorbic acid and furanic compounds by HPLC-dual detection. Food Chem. 64, 423-427. 